\title{
Prospects of Organic Farming in Bhutan: A SWOT Analysis
}

\author{
Sonam Tashi ${ }^{1}$ and Kesang Wangchuk ${ }^{2}$ \\ ${ }^{1}$ College of Natural Resources, Royal University of Bhutan, Lobesa, Wangdue, Bhutan \\ ${ }^{2}$ Renewable Natural Resources Research and Development Center, Ministry of Agriculture and Forests, Bumthang, Bhutan \\ Correspondence should be addressed to Kesang Wangchuk; kesangwangchuk@rocketmail.com
}

Received 15 March 2016; Revised 23 May 2016; Accepted 20 June 2016

Academic Editor: Claus A. Soerensen

Copyright (C) 2016 S. Tashi and K. Wangchuk. This is an open access article distributed under the Creative Commons Attribution License, which permits unrestricted use, distribution, and reproduction in any medium, provided the original work is properly cited.

A study was conducted to investigate the prospects of organic agriculture (OA) in Bhutan from the experts' perspective, particularly the SWOT (strength, weakness, opportunity, and threat) aspect. Thirty-five Bhutanese experts were interviewed. The strengths of OA were (i) good alignment of the principles of OA with Bhutan's development philosophy, (ii) strong policy and political support, (iii) pristine environment, (iv) OA practices similar to traditional farming, and (v) compatibility of OA with the local farming knowledge. The major weaknesses were (i) a lack of awareness of the benefits of OA, (ii) lack of incentives, (iii) shortage of farm labor, (iv) small and irregular supply of organic product, (v) lack of clarity in policy, (vi) limited plant protection materials, and (vii) a lack of coordination between agencies. Opportunities were (i) a huge regional and global organic market, (ii) promoting healthy lifestyle, (iii) sustainable use of resources, (iv) lowering dependence on food and input imports, (v) development of local organic manure suppliers, (vi) creating seed sovereignty, (vii) conserving local crops, (viii) building soil fertility, (ix) introducing premium price for organic products, and (x) addressing unemployment. Threats included (i) increasing incidences of pests and diseases, (ii) decline in sources of organic manure, and (iii) limited sources of organic manures and fertilizers.

\section{Introduction}

Organic agriculture $(\mathrm{OA})$ is a sustainable approach to food production as it includes all agricultural systems that promote the environmentally, socially, and economically sound production of food and fibers $[1,2]$. Organic agriculture is socially acceptable, economically sound, and environmentally benign than conventional agriculture [3-6]. OA favours animal welfare, preserves biodiversity $[4,7]$, and reduces resource consumption [8]. OA also emphasizes sustainability in theory and practice and has attracted many environmentalists and health conscious consumers [9]. The rising number of organic consumers in turn has triggered further growth of organic agricultural land and the organic market $[10,11]$. In tandem with the increase in land under OA, the global organic market also rose to US \$64 billion in 2012 from US $\$ 18$ billion in 2000 [11]. The growing global OA movement, which is predicted to grow further [11] because of the continuing environmental ill effects and contentious poor food quality emanating from conventional farming, has lured the Himalayan Kingdom of Bhutan into its fold.
However, the agriculture professionals and policy makers remain sceptical on whether the combination of philosophy of Gross National Happiness (GNH) and practice of OA can actually lead to a total conversion. Can OA deliver Bhutan's much sought-after food self-sufficiency goal? Several studies conducted elsewhere contest the benefits associated with OA [12-14]. These studies argue that the yield and profit from OA are low and soils are nutrient-deficient, and hence the organic production system is alleged to be inefficient and not capable of meeting the food demand of the growing global population $[12,14]$. On the other hand, there are approximately an equal number of studies with opposing claims [15-17].

Bhutan's development philosophy of Gross National Happiness (GNH) embraces environment protection and sustainable socioeconomic development through cautious planning. Despite being economically poor and experiencing food deficit, Bhutan's development policy objectives, guided by the philosophy of GNH, remain all-inclusive and sustainabilityoriented [18]. The holistic approach of OA to food production with a strong emphasis on sustainability has much in 
TABLE 1: Types of participants involved in the study.

\begin{tabular}{lcc}
\hline Sl. number & Type of participant & Number of participants \\
\hline 1 & Policy makers & 5 \\
2 & Organic farmers & 5 \\
3 & Agriculture specialists & 8 \\
4 & Academicians & 7 \\
5 & Private sector & 5 \\
6 & Cooperatives & 5 \\
\hline
\end{tabular}

common with the philosophies and aspirations of policy objective of GNH. Accordingly, Bhutan officially launched $\mathrm{OA}$ in 2003 and proclaimed the intention to become a fully organic country by the year $2020[19,20]$. The theory and practice of organic farming, which exclude or restrict the use of synthetic agrochemicals and encourage crop rotation and diversification, go hand in hand with farming practices in the country $[21,22]$. Generally, the Bhutanese farmers rely heavily on traditional knowledge that advocates the use of organic materials such as cattle manure, leaf litter, and crop residues as fertilizers. These attributes put Bhutan in a rather comfortable position to convert to fully organic agricultural production [23] without major shifts in the prevailing farming paradigm. Bhutan's aspiration to become a fully organic country is backed by strong political support, both within and outside the country [20].

Given a set of constraints prevalent in Bhutan, it is unclear how and to what technological, management, and social extent OA can meet the expectations of enhancing food production and lowering production costs, while maintaining the soil fertility in the country. We conducted a study with a primary objective to investigate the prospects of $\mathrm{OA}$ from the perspective of agriculture experts' only, focusing mainly on strengths, weaknesses, opportunities, and threats of OA. The second objective was to gather opinions on the promotion of $\mathrm{OA}$ and transitioning of Bhutan to a fully organic country.

\section{Materials and Methods}

2.1. Expert Group Discussion. An expert interview approach was adopted to gather information. Expert interviews were considered as an efficient and concentrated method of gathering data, especially in exploratory phase of a project [24]. Prior to interview, the two ethical bodies, namely, the Council for Renewable Natural Resources Research of Bhutan and the Royal University of Bhutan, assessed and approved the research design for human research ethics.

An expert group workshop and personal interviews were held amongst 35 member participants comprising policy makers, organic farmers and agriculture specialists, academia and private sector, and cooperative representatives (Table 1). Participants interviewed for this research work had vast experience in both national and international organic and inorganic agriculture. The interactive session was held in Thimphu, the capital city of Bhutan, and covered topics and questions related to organic farming policies, research, challenges, and future prospects, amongst others.
2.2. Analysis of Strengths, Weaknesses, Opportunities, and Threats (SWOT). A SWOT analysis [25] was employed for evaluating the strengths, weaknesses, opportunities, and threats involved in OA. Strengths, weaknesses, opportunities, and threats were defined by experts based on the current agriculture production scenario and development policies in Bhutan. Of the several SWOT issues, only 8 strengths, 13 weaknesses, 16 opportunities, and 8 threats were selected and used for interviewing experts. The selection was based mainly on the relation of SWOT issues with the GNH development policy. The SWOT analysis was chosen since it is a structured planning method usually used at the planning stage to assess and identify both the internal and external factors that are favourable or unfavourable towards achieving the goals of a venture or project. Knowledge and information collected through interviews were used as the main input for the SWOT analysis. With the SWOT analysis, both helpful and harmful factors that originated from both internal and external factors of OA were examined. Strengths were categorized as internal helpful factors and weaknesses as internal hindering factors of OA. Opportunities were external helpful factors and threats the external harmful factors. The various parameters for strengths, weaknesses, and opportunities used by the participants group are presented in the following list. The SWOT issues were defined based on future expectations from $\mathrm{OA}$ in Bhutan and not from scientific literatures.

The list of strengths, weaknesses, opportunities, and threats of OA in Bhutan is as follows.

\section{Strengths}

(1) Principles of OA aligning well with the philosophy of GNH.

(2) Strong policy support.

(3) Strong political support.

(4) Similarity to traditional farming.

(5) Pristine environment.

(6) Compatibility with good local farming knowledge.

(7) Strong national organic program.

(8) Increasing international support.

\section{Weaknesses}

(1) High production cost.

(2) Lack of awareness of benefits of OA.

(3) Lack of clarity in policy.

(4) Labor shortage.

(5) Lack of coordination between different agencies.

(6) Limited technical expertise.

(7) Lack of certification.

(8) Poor soil fertility.

(9) Lack of quality planting materials.

(10) Nascent research in OA.

(11) Small/irregular supply of organic produce. 


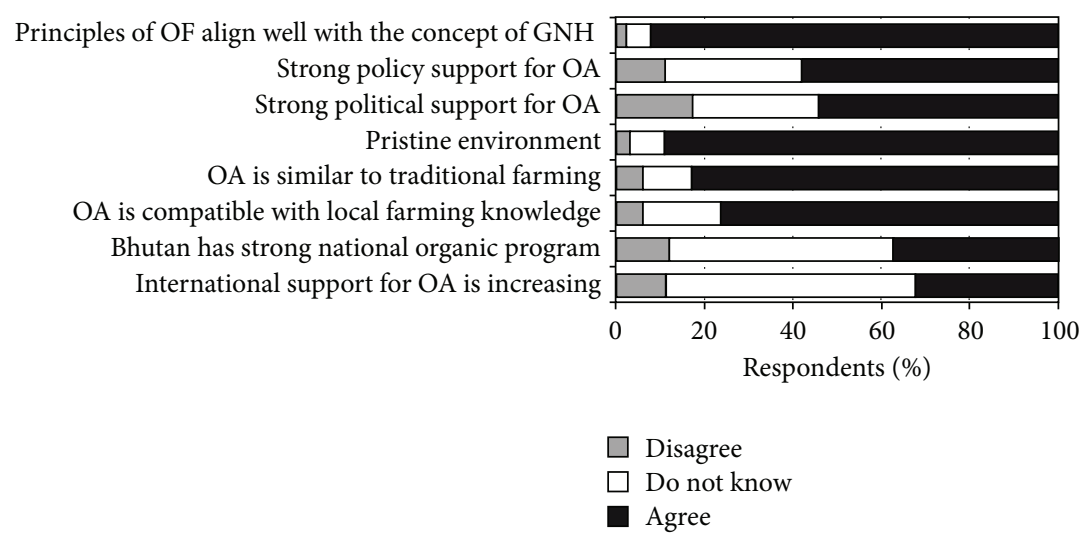

FIGURE 1: Strengths of OA in Bhutan as mentioned by agriculture participants.

(12) Limited plant protection options.

(13) Lack of incentives.

\section{Opportunities}

(1) Promoting healthy lifestyle.

(2) Sustainable use of resources.

(3) Developing local organic manure suppliers.

(4) Huge regional export market.

(5) Huge global export market.

(6) Creating seed sovereignty.

(7) Conserving local crops.

(8) Strengthening culture.

(9) Promoting self-sufficiency and food reliance.

(10) Reducing dependence on import.

(11) Growing interest in OA.

(12) Premium price.

(13) Building up soil fertility.

(14) Consistent yield.

(15) Strengthening rural community.

(16) Employment opportunities.

\section{Threats}

(1) Impending WTO membership.

(2) Global competition.

(3) Variability in climate pattern.

(4) Yield reduction.

(5) Dwindling supply of organic sources of manure.

(6) Pest and disease incidence.

(7) Higher certification cost.

(8) Introduction of genetically modified organisms (GMOs).
Participants were given a set of questionnaires, where they were requested to answer questions on whether Bhutan should promote organic farming, precautions to be taken when going fully organic, and possibility of successful transition to a fully organic country. The questionnaire also sought participants' agreement and disagreement on SWOT of organic farming in Bhutan. To simplify information, the participants' opinions were recorded on a three-point Likert scale [26] against the commonly used five-point scale. The use of three-point Likert scale was justified since reliability and validity of information were found to be independent of the scale points employed by Likert-type items [27].

Questions were asked on Bhutan transitioning to a fully organic country. Participants provided opinions on whether Bhutan should promote organic farming, whether it will be possible for Bhutan to convert to a fully organic country, and whether Bhutan should phase out synthetic agrochemicals (SACs) completely.

2.3. Data Analysis. Chi-square tests were performed to evaluate differences in opinions of the respondents. These opinions are displayed in percentages of respondents. The entire dataset was analysed with SPSS 23 [28].

\section{Results}

3.1. Strengths. The strengths of OA are provided in Figure 1. Over $90 \%$ of participants agreed that the principles of OA align and blend well with the developmental policy objective and philosophy of Bhutan's GNH. Over half of the participants agreed that Bhutan has a strong policy as well as political support for OA. Similarly, over $80 \%$ of participants highlighted Bhutan's pristine environment as a strength favourable for OA. About same proportion of participants were also in agreement with strength of OA being similar to traditional farming. According to over three quarters of participants, $\mathrm{OA}$ is compatible with the local farming knowledge. Over half of participants did not know whether the national organic program is strong enough in the country to support OA. About same proportion of 


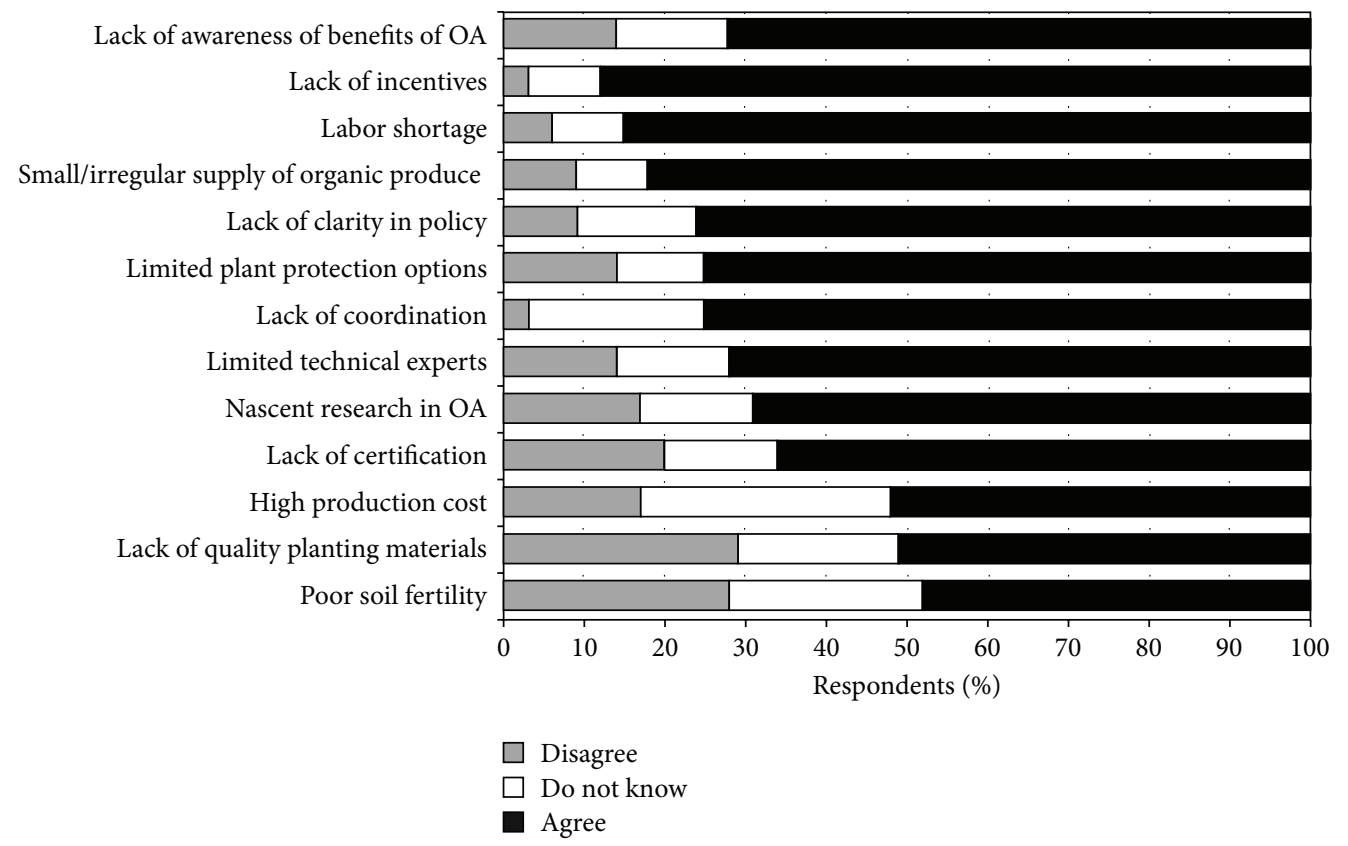

Figure 2: Weaknesses of OA in Bhutan as mentioned by agriculture participants.

participants also did not know whether the international support for $\mathrm{OA}$ is increasing.

3.2. Weaknesses. The weaknesses of $\mathrm{OA}$ are presented in Figure 2. Amongst weaknesses, the lack of awareness on benefits of OA, lack of incentives, shortage of farm labor, and small and irregular supply of organic produce featured more prominently (over $80 \%$ of the participants). A vast majority of participants mentioned the lack of clarity in policy, limited plant protection materials, and lack of coordination between agencies as major weaknesses. Limited technical experts and lack of research culture in Bhutan were found to be the weaknesses of OA. Other weaknesses were lack of product certification, high production cost, lack of quality planting materials, and poor soil fertility.

3.3. Opportunities. Figure 3 presents the opportunities of $\mathrm{OA}$ in Bhutan. A large majority of participants strongly felt that OA has an opportunity to promote healthy lifestyle and sustainable use of resources. Most participants agreed that $\mathrm{OA}$ will provide opportunity to curb dependence on food and input imports. Participants agreed that there are opportunities to develop local organic manure suppliers, create seed sovereignty, conserve local crops, build soil fertility, and introduce premium price for organic products. These opportunities may promote food sufficiency, which was mentioned as another opportunity of OA.

A large majority of participants agreed that there is a huge global and regional market for organic produce. Interest in $\mathrm{OA}$ is growing due to consistent crop yield. About half of the participants felt that OA has opportunities to strengthen rural community and provide better opportunity to address unemployment for Bhutanese youth.
3.4. Threats. A number of threats Bhutan might encounter in promoting OA are presented in Figure 4 . About $70 \%$ of participants felt that the increasing incidences of pests and diseases and decline in sources of organic manure could be the biggest threats to OA. Limited sources of organic manures and fertilizers and their likely decline also featured as the second biggest threat to OA. The other two important threats that most participants unanimously agreed on were variability in climate and yield reduction, which are feared to compromise food self-sufficiency. A majority (62\%) of participants identified the high cost of organic certification, impending World Trade Organization (WTO) membership, and global competition as threats to OA. Participants were divided on the introduction of genetically modified organisms (GMOs) as a threat, since the issue is still being debated.

3.5. Promotion of $O A$ and Transitioning to a Fully Organic Country. A large majority (94\%) of participants supported the promotion of OA in Bhutan (Table 2). On the question of whether or not Bhutan can convert to a fully organic country, only $36 \%$ of participants were sure and $64 \%$ either were not sure or did not agree.

Only about one-third of the participants were in favour of phasing out all SACs from the country as planned by the government. The other two-thirds of the participants either were not in favour of phasing out all the SACs from the country or were not sure.

\section{Discussion}

4.1. Strengths. The vast majority of participants agree that the principles of OA align and blend well with the developmental policy objective and philosophy of Bhutan's GNH. This 


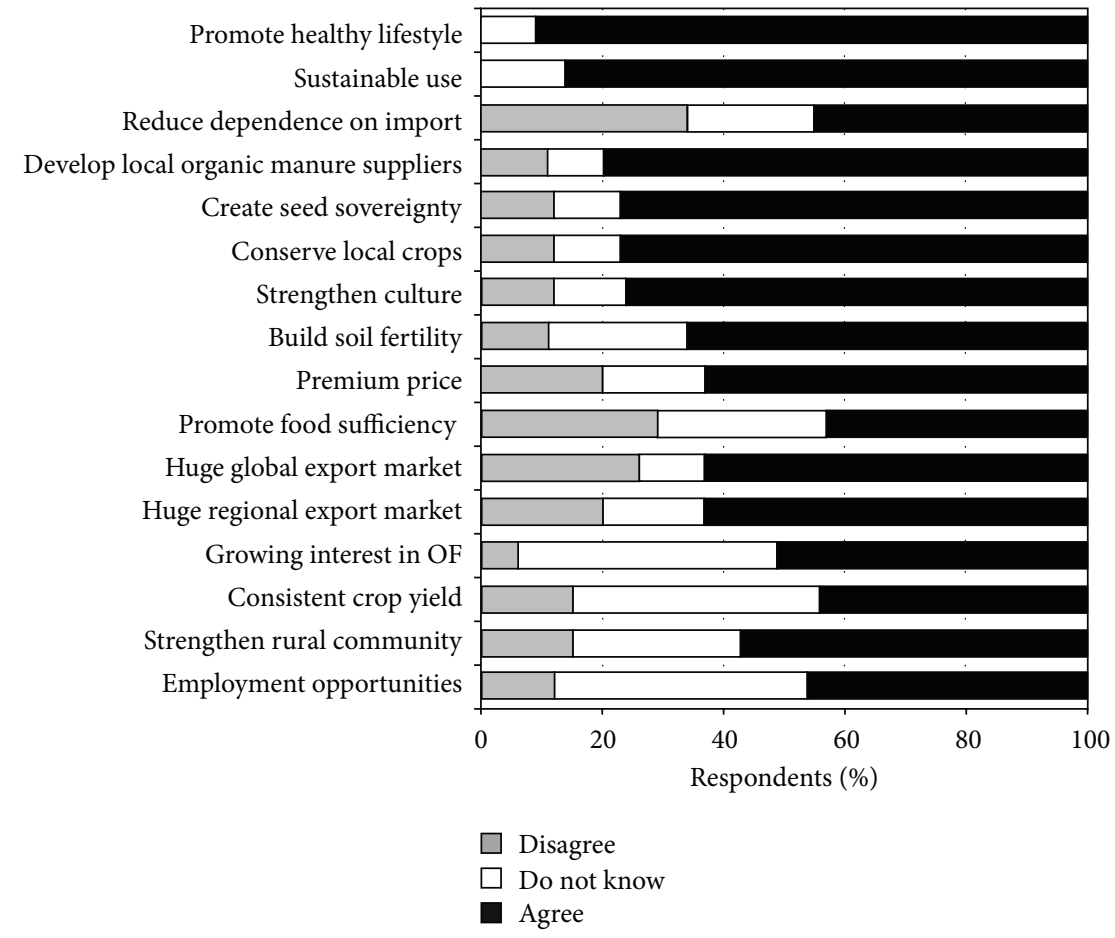

FIGURE 3: Opportunities of OA in Bhutan as mentioned by agriculture participants. OF = OA.

TABLE 2: Questions and respondents' opinions on transitioning to a fully organic country.

\begin{tabular}{|c|c|c|c|}
\hline \multirow{2}{*}{ Question } & \multicolumn{3}{|c|}{ (\%) } \\
\hline & Yes & No & Not sure \\
\hline Should Bhutan promote organic farming? & 94 & 0 & 6 \\
\hline Will it be possible for Bhutan to convert to a fully organic country? & 36 & 24 & 40 \\
\hline Should Bhutan phase out SACs in its entirety? & 30 & 38 & 32 \\
\hline
\end{tabular}

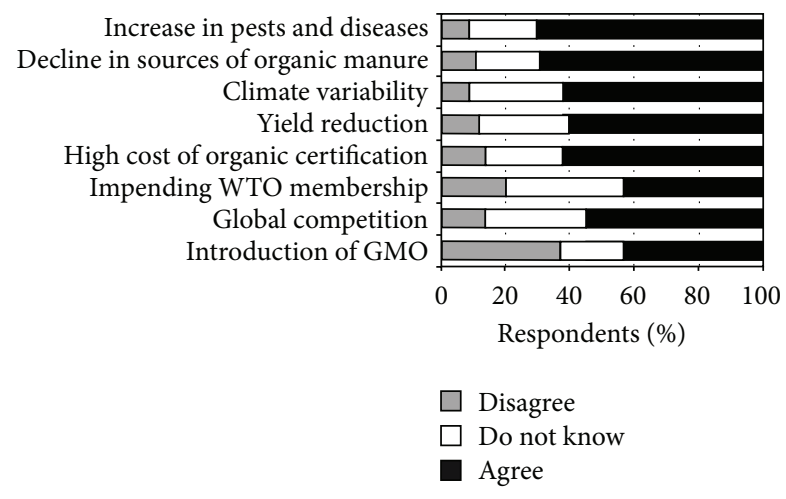

FIGURE 4: Threats of OA in Bhutan as mentioned by agriculture participants.

is due to the fact that the GNH concept hinges on four pillars, namely, good governance, sustainable socioeconomic development, cultural preservation, and environmental conservation $[18,29]$. These pillars conform to the four principles of $\mathrm{OA}[30]$ because the principles and philosophies of OA share the same values of sustaining not only the economy but also the social and environmental aspects of well-being.
The four principles of organic farming provide insights into philosophies of organic production and also form guidelines for its practices [16]. The philosophies revolve around ethical principles, mainly because people interact with living landscapes and relate to one another [31]. This probably explains why Bhutan has a strong policy as well as political support for OA, which is viewed as a strength. The policy support for OA has been demonstrated by the launching of the national organic program (NOP) in 2006 and the government's proposal for tax exemption of 5-10 years for commercial organic farming and processing of organic products [30]. The participants' agreements on strengths match well with a provision in the Bhutanese Constitution, which outlines the promotion of conditions enabling the pursuit of GNH.

Similarly, Bhutan's pristine environment is considered as a strength favourable for OA. The intact and pristine environment provides favourable preconditions for the production of a wide range of food and fiber. The pristine environment is compatible with $\mathrm{OA}$ and the interactions of environment and OA may complement each other in sustaining the health of soils, ecosystems, and people. Besides, OA relies on ecological processes, biodiversity, and cycles adapted to local conditions, rather than the use of external inputs with adverse effects [31]. 
OA was also found to be similar to the traditional farming. It reflects $\mathrm{OA}$ as a system combining tradition, innovation, and science to benefit the shared environment and promote fair relationships and a good quality of life [31]. OA was felt to be compatible with the local farming knowledge, which suggests the greater likelihood of Bhutanese farmers to accept the idea and promotion of OA without marked changes in the traditional farming practices. In Bhutan, a large majority of farmers practice organic farming by default and this places Bhutan in a vantage and unique position to convert to a fully organically farming country. Studies done in many parts of Africa and India have shown that smallholder organic-by-default farmers can easily convert to OA without compromising yield or other associated benefits $[3,9,22]$.

As a symbol of commitment to become fully organic, Bhutan established the national organic program (NOP) in 2006 [30] and launched the National Framework Organic Farming in Bhutan (NFOFB) in 2007. The NFOFB and NOP were entrusted to develop and promote organic farming and environmentally friendly farming systems as a way of life and to produce high quality and safe food, for both domestic and export markets [19]. Despite the existence of such program, it is unclear whether the national organic program is strong enough in the country to support OA. The participants' expression likely indicates the infancy of the NOP's initiatives and lack of technical expertise to bring about marked changes in $\mathrm{OA}$.

4.2. Weaknesses. The weaknesses are primarily because OA practices based on scientific knowledge are fairly new in Bhutan. Since it is a new farming practice, weaknesses may have resulted from a lack of awareness of the potential benefits of OA as well as a lack of technical expertise at all levels. Although the lack of clarity in policy features is a weakness, a more in-depth analysis reveals that important tools to promote OA have already been instituted. These include the establishment of the national organic program (NOP) and the Technical Working Group, while standards for OA and an Internal Control System were in the last stages of finalization at the time of this research. Many other policies that favour OA have already been put in place [32].

Limited plant protection materials and lack of coordination between agencies are clear signs of infancy of $\mathrm{OA}$ in Bhutan. Lack of coordination between agencies and limited technical experts would mean there is a need for the concerned institutions to come to a common platform and proactively strengthen themselves with competent technical experts to formulate practical approaches and plans. Lack of research culture in Bhutan is another barrier to the development of competencies and technologies [33]. This could add further weakness in that viable alternatives to synthetic plant protection chemicals such as effective biopesticides are presently not adequately researched in the country. Weaknesses such as high production cost, lack of quality planting materials, and poor soil fertility can be addressed largely through scientific research. Addressing these weaknesses will probably demand time and investment to develop appropriate and viable alternatives, such as labor saving devices to overcome labor shortage and reduce production costs, and provisioning of quality planting materials and other inputs at affordable prices.

4.3. Opportunities. Bhutan has many opportunities primarily due to growing interest and awareness in OA and an increasing regional and global organic market. OA has an opportunity to promote healthy lifestyle and sustainable use of resources. While OA might appeal to most Bhutanese whose consciousness for better health is growing, OA will provide opportunity to boost sustainable use of natural resources and curb dependence on food and input imports. Opportunities are likely to lower dependence on food and input imports and are expected to promote food sufficiency. The experience on OA gathered from around the world, particularly from developing countries, and smallholder family farms with which Bhutan shares many commonalities suggests that OA would be in a better position to achieve food self-sufficiency and security. This is because OA is diversified, robust, and of low cost due to the exclusion of external inputs and energy $[22,34,35]$.

The global and regional markets for organic produce are likely to be huge. The huge markets stem mainly from increasing demand for healthy food coupled with the growing scare of environmental pollution and damage $[22,36]$, which is pushing the growth of organic farming worldwide. The growing demand for organic food is manifested in the total global area under organic farming, which has increased from 29 million ha in 2005 to 37.5 million ha in 2012 [17]. The total market values have also seen corresponding growth from about US \$29 billion in 2004 to US \$64 billion in 2012. The global development in OA predicts better opportunities for huge regional and internal markets for organic produce. This could help organic produce of Bhutan to find more customers both within and outside the country and foster growth of rural economy. OA has lesser risk since it is known to provide consistent crop yield. OA provides better opportunity to address unemployment for Bhutanese youth. Tashi and Wangchuk [37] reported that organic rice production demands more manual labor, which suggests that this type of production can generate more employment for rural youth.

4.4. Threats. Increasing incidences of pests and diseases and decline in sources of organic manure could be the biggest threats to OA. Pest attack and disease outbreaks are important constraints, which continue as a constant challenge for both organic and conventional farmers. OA cannot rule out the possibility of pest and disease pressure arising from the lack of improved varieties, unavailability of effective biopesticides when required, and to some extent poorer plant health.

Limited sources of organic manures and fertilizers and their likely decline are the second biggest threats to OA. This could be linked to the traditional practices of fertilization by the Bhutanese farmers. Cattle manure and leaf litter from forests are the major traditional sources of manures and fertilizers in Bhutan. It is a common practice for the cattle to graze in the forest, and through dung deposit, cattle act as a carrier of plant nutrients from forest to cropland [38]. Farmers also collect leaf litter from forest floor to fertilize crop fields. A study by Roder et al. [38] highlights the fear of likely 
decline in forest resources due to these traditional practices for several years without nutrient replacement.

Variability in climate and yield reduction were also important threats, which are feared to compromise food selfsufficiency. Variability in climate pattern, coupled with the lack of viable alternatives in plant protection under OA, might seriously reduce yield and may threaten the government's goal of achieving food self-sufficiency. Scientific models predict substantial changes in climate due to increased emission of greenhouse gases. Although the organically managed farms are said to be better adapted and resilient to climate change, the extreme weather and seasonal variations in weather events such as drought, flood, and soil erosion are expected to pose serious threats to traditional methods of crop production. Bhutan, as one of the mountainous countries, is vulnerable and is expected to suffer most from climate change.

High cost of organic certification and impending World Trade Organization (WTO) membership are also threats to $\mathrm{OA}$. This may be true because certification is an expensive affair and there are many other costs beyond the actual organic application. The other costs during the certification process include payment for inspections, assessments, and travel costs, in addition to annual renewal fees. In light of these expenses to be covered for several farms in the country, the high certification cost poses a question whether Bhutan, as a least developed country, can afford to meet these expenses annually and live up to the international standards of OA. Further, several countries are getting certified as producers of organic food leading to stiff competition in the global market, which is seen by a majority of participants as another threat to OA in Bhutan.

The issue on the introduction of genetically modified organisms (GMOs) is still being debated; therefore, opinions were divided on this as a threat. While some participants argued that GMOs are high yielding and tolerant to drought, salinity, and pests and diseases, there were others who alleged GMOs to result in the upsurge of more virulent pests and diseases, which are similar to the findings of Shiva [39]. Roder et al. [38] also expressed fear over GMOs eroding traditional varieties and creating dependency, which could become an expensive affair.

4.5. Promotion of $O A$ and Transitioning to a Fully Organic Country. The promotion of OA in Bhutan appears to receive strong support. The support stems primarily from the growing awareness of the harmful effects of SACs on soil, water, environment, and human and animal health. Promotion of OA would be in line with the country's GNH philosophy, and it would be contradictory to GNH, if Bhutan did not promote OA. Bhutan also has the right conditions for the promotion of OA because a large majority of the farmers are organic-by-default and farming is chiefly traditional, characterized by small landholding and subsistence farming. However, there is also a question on whether Bhutan should promote OA. The question arises mainly due to the fact that $\mathrm{OA}$ is still seen as low yielding and expensive and might exacerbate the prevailing food deficit. Such attitudes may challenge and potentially slow the promotion of OA.
Thus, such outlook merits a healthy and transparent dialogue amongst stakeholders.

Before Bhutan converts to a fully organic country, our findings suggest a need to put in place the necessary structures, sound policy directives, human capital, and exigency plans in the event if the conversion to organic country flounders. By far, the most feared reasons for harboring reservations against converting to a fully organic country are the expected reduction in yield and the rise in pest and disease levels. This line of thinking suggests that there are no effective organic alternatives to enhancing yield and warding off pests and diseases. This might explain why the country should not entirely phase out SACs. Rather than eliminating SACs in their entirety, regulating the use of SACs and more importantly encouraging the mixed use of organic and synthetic inputs and interventions are suggested. In essence, despite supporting the promotion of OA in Bhutan, many still feel that the conversion to a fully organic country will not be possible or do not support phasing out SACs entirely, which otherwise could be one of the shortest and fastest ways towards converting to a fully organic country.

\section{Conclusions}

Bhutan possesses a considerable array of opportunities and strengths in promoting OA. However, there are several threats and weaknesses, the majority of which are essentially not unique to $\mathrm{OA}$ alone. Bhutan needs to seriously consider addressing the weaknesses and invent effective mechanisms to offset threats of OA. Currently, the pros and cons of OA draw mixed reactions to the idea of promoting OA in Bhutan. Lack of trustworthy policy mechanism, adequate human capacity, and infrastructure are hurdles to Bhutan transitioning to a fully organic country. Without these arrangements in place, the plan of Bhutan becoming a fully organic country by the year 2020 might remain far-fetched.

\section{Abbreviations \\ GNH: Gross National Happiness \\ GMOs: Genetically modified organisms \\ OA: Organic agriculture \\ NFOFB: National Framework Organic Farming in Bhutan \\ NOP: National organic program \\ SACs: Synthetic agrochemicals \\ SPSS: $\quad$ Statistical Package for Social Sciences \\ SWOT: Strength, weakness, opportunity, and threat \\ WTO: World Trade Organization.}

\section{Disclosure}

No written and informed consent was obtained for publication of the data; therefore, age and sex were removed to maintain the anonymity of the participants.

\section{Competing Interests}

The authors declare that they have no competing interests. 


\section{Authors' Contributions}

Dr. Sonam Tashi conceived the study, designed the survey, analysed the data, and wrote most of the paper. Dr. Kesang Wangchuk assisted in data analysis and contributed to the writing of the paper. Both authors read and approved the final paper.

\section{Acknowledgments}

The authors gratefully acknowledge the financial assistance of the German Academic Exchange Service (DAAD/BMZ) and Fiat Panis Foundation. The authors are also grateful to the Centre for Development Research (ZEF), the University of Bonn, Germany, and the College of Natural Resources under the Royal University of Bhutan, for their invaluable support to this study. The authors thank thirty-five agriculture specialists, policy makers, and NGO and private sector representatives of Bhutan for sparing their time to expert group interviews and discussions. The authors express their heartfelt thanks to the ethical bodies, the Council for Renewable Natural Resources Research of Bhutan, Ministry of Agriculture and Forests, and the Royal University of Bhutan, for approving the study design involving humans. The ethical approval was given after the research design complied with the Declaration of Helsinki.

\section{References}

[1] I. F. O. A. M (International Federation of Organic Agriculture Movements), IFOAM Basic Standards, International Federation of Organic Movements, Tholey-Theley, Germany, 2000.

[2] FAO, "Organic agriculture," http://www.fao.org/organicag/oafaq/oa-faq1/en/.

[3] N. E.-H. Scialabba, "Organic agriculture and food security," in Proceedings of the International Conference on Organic Agriculture and Food Security, FAO, Rome, Italy, May 2007.

[4] G. Rahmann, "Biodiversity and organic farming: what do we know?" Landbauforschung Volkenrode, vol. 61, no. 3, pp. 189208, 2011.

[5] UNEP, Organic Agriculture-A Step towards the Green Economy in the Eastern Europe, Caucasus and Central Asia Region: Case Studies from Armenia, Moldova and Ukraine, United Nations Environmental Programme, Geneva, Switzerland, 2011.

[6] H. L. Tuomisto, I. D. Hodge, P. Riordan, and D. W. Macdonald, "Does organic farming reduce environmental impacts? A meta-analysis of European research," Journal of Environmental Management, vol. 112, pp. 309-320, 2012.

[7] D. G. Hole, A. J. Perkins, J. D. Wilson, I. H. Alexander, P. V. Grice, and A. D. Evans, "Does organic farming benefit biodiversity?” Biological Conservation, vol. 122, no. 1, pp. 113-130, 2005.

[8] T. Nemecek, D. Dubois, O. Huguenin-Elie, and G. Gaillard, "Life cycle assessment of Swiss farming systems: I. Integrated and organic farming," Agricultural Systems, vol. 104, no. 3, pp. 217-232, 2011.

[9] FAO, Organic Agriculture, Environment and Food Security, FAO, Rome, Italy, 2013.

[10] P. Kristiansen and C. Merfield, "Overview of organic agriculture," in Organic Agriculture-A Global Perspective, P. Kristiansen, A. Taji, and J. Reganold, Eds., CSIRO Publishing, Collingwood, Australia, 2006.
[11] FiBL-IFOAM, The World of Organic Agriculture, FiBL, Frick, Switzerland; IFOAM, Bonn, Germany, 2014.

[12] H. Kirchmann, L. Bergström, T. Kätterer et al., "Can organic crop production feed the world?" in Organic Crop ProductionAmbitions and Limitations, H. Kirchmann and L. Bergström, Eds., Springer, Dordrecht, Netherlands, 2008.

[13] H. J. L. Jenkins, J. R. Godwin, B. Pearce et al., "A comparison between conventional and organic farming practice," in Proceedings of the 19th World Congress of Soil Sciences, Soil Solutions for a Changing World, pp. 1-4, Brisbane, Australia, 2010.

[14] V. Seufert, N. Ramankutty, and J. A. Foley, "Comparing the yields of organic and conventional agriculture," Nature, vol. 484, no. 7397, pp. 229-232, 2012.

[15] T. C. Mendoza, M. L. Pecadizo, and W. L. D. L. Santos, "Comparative case study of organic LEISA and conventional rice farming systems in Quezon province, Philippines," Philippine Journal of Crop Science, vol. 26, no. 2, pp. 35-40, 2001.

[16] N. Nemes, Comparative Analysis of Organic and Non-Organic Farming Systems: A Critical Assessment of Farm Profitability, Food and Agriculture Organization, UN, Rome, Italy, 2009.

[17] C. Qing-gen and W. Lei, "Study on contribution of potassium, nitrogen and organic fertilizers matter," Agriculture Science and Technology, vol. 12, no. 9, pp. 1381-1384, 2011.

[18] K. Ura, S. Alkire, T. Zangmo et al., A Short Guide to Gross National Happiness Index, The Centre for Bhutan Studies, Thimphu, Bhutan, 2012.

[19] National Framework for Organic Farming in Bhutan, Ministry of Agriculture, Thimphu, Bhutan, 2007.

[20] Y. J. Thinley, “Statement on Bhutan's Organic Policy, Department of Agriculture, Ministry of Agriculture and Forests, Royal Government of Bhutan, pp. 1-3, 2011.

[21] A. Thimmaiah, A Guide to Organic Agriculture in Bhutan, Ministry of Agriculture, Royal Government of Bhutan, Thimphu, Bhutan, 2007.

[22] K. Pradhan, T. Samdrup, and R. T. Gurung, Towards Food Security: Challenges and Strategies for Bhutan, Food Security on Anthroplogical Perspective, Osaka, Japan, 2012.

[23] A. Leu, "Smallholder organic farming versus GMOs," Ecology and Farming, vol. 51, 2011.

[24] A. Bogner, B. Littig, and W. Menz, "Introduction: expert interviews-an introduction to a new methodological debate," in Interviewing Participants, A. Bogner, B. Littig, and W. Menz, Eds., pp. 1-13, Palgrave Macmillan, New York, NY, USA, 2009.

[25] A. Humphrey, "SWOT analysis for management consulting," SRI Alumni Newsletter, vol. 1, pp. 7-8, 2005.

[26] Likert, "A technique for the measurement of attitudes," Archives of Psychology, vol. 140, pp. 1-55, 1932.

[27] J. Jacoby and M. S. Matell, "Three-point likert scales are good enough," Journal of Marketing Research, vol. 8, no. 4, pp. 495$500,1971$.

[28] S. Landau and B. S. Everitt, A Handbook of Statistical Analyses Using SPSS, FL Chapman \& Hall/CRC, Boca Raton, Fla, USA, 2004.

[29] G. S. Tideman, "Gross national happiness," in Ethical Principles and Economic Transformation-A Buddhist Approach, L. Zsolnai, Ed., vol. 33, pp. 133-154, Springer, Dordrecht, Netherlands, 2011.

[30] K. Tshomo, Bhutan's Status on Development Strategy for Organic Sector, International Organic and Ecological Agriculture in Mountain Ecosystems, Thimphu, Bhutan, 2014. 
[31] I. F. O. A. M, Basic Standards for Organic Production and Processing, International Federation of Organic Agriculture Movements, Tholey-Theley, Germany, 2002.

[32] S. Tashi, Organic Nutrient Management of Citrus Mandarin for Bhutan, University of Melbourne, Melbourne, Australia, 2007.

[33] D. Neuhoff, S. Tashi, G. Rahmann, and M. Denich, "Organic agriculture in Bhutan: potential and challenges," Journal of Organic Agriculture, vol. 4, no. 3, pp. 209-221, 2014.

[34] K. Lyons and D. Burch, "Socio-economic effects of organic agriculture in Africa," in Proceedings of the 16th IFOAM Organic World Congress, Modena, Italy, 2008.

[35] A. Leu, Adaptation for Farmers-Building Climate Change Resilience through Organic Systems, 2011.

[36] D. J. Connor, "Organic agriculture cannot feed the world," Field Crops Research, vol. 106, no. 2, pp. 187-190, 2008.

[37] S. Tashi and K. Wangchuk, "Organic vs. conventional rice production: comparative assessment under farmers' condition in Bhutan," Organic Agriculture, 2015.

[38] W. Roder, K. Dorji, and G. Gratzer, "Nutrient flow from the forest-source of life for traditional Bhutanese agriculture," Austrian Journal of Forest Science, vol. 1, pp. 65-72, 2003.

[39] V. Shiva, The Seeds of Suicide: How Monsanto Destroys Farming, Global Research, 2013. 


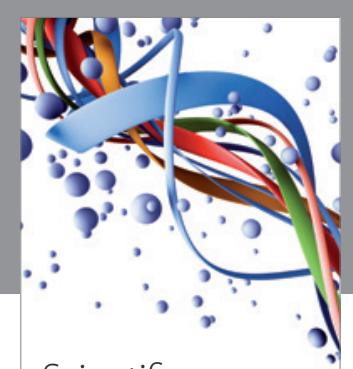

Scientifica
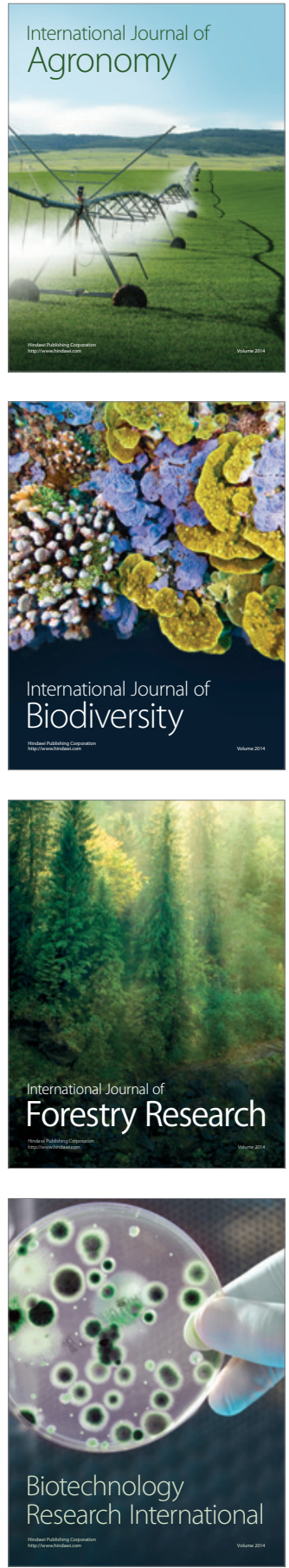
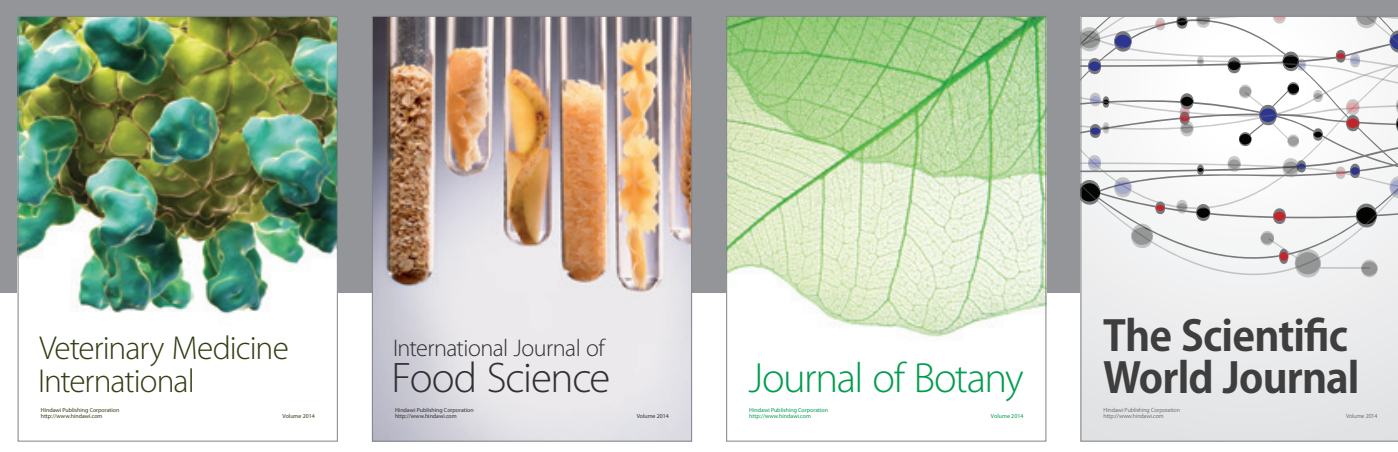

The Scientific

\section{World Journal}

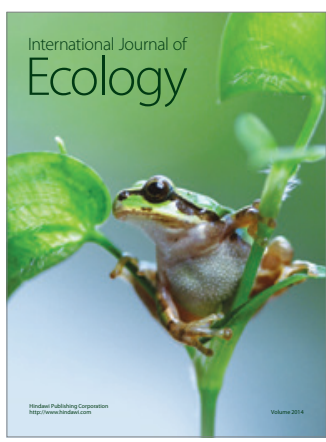

\section{Hindawi}

Submit your manuscripts at

http://www.hindawi.com
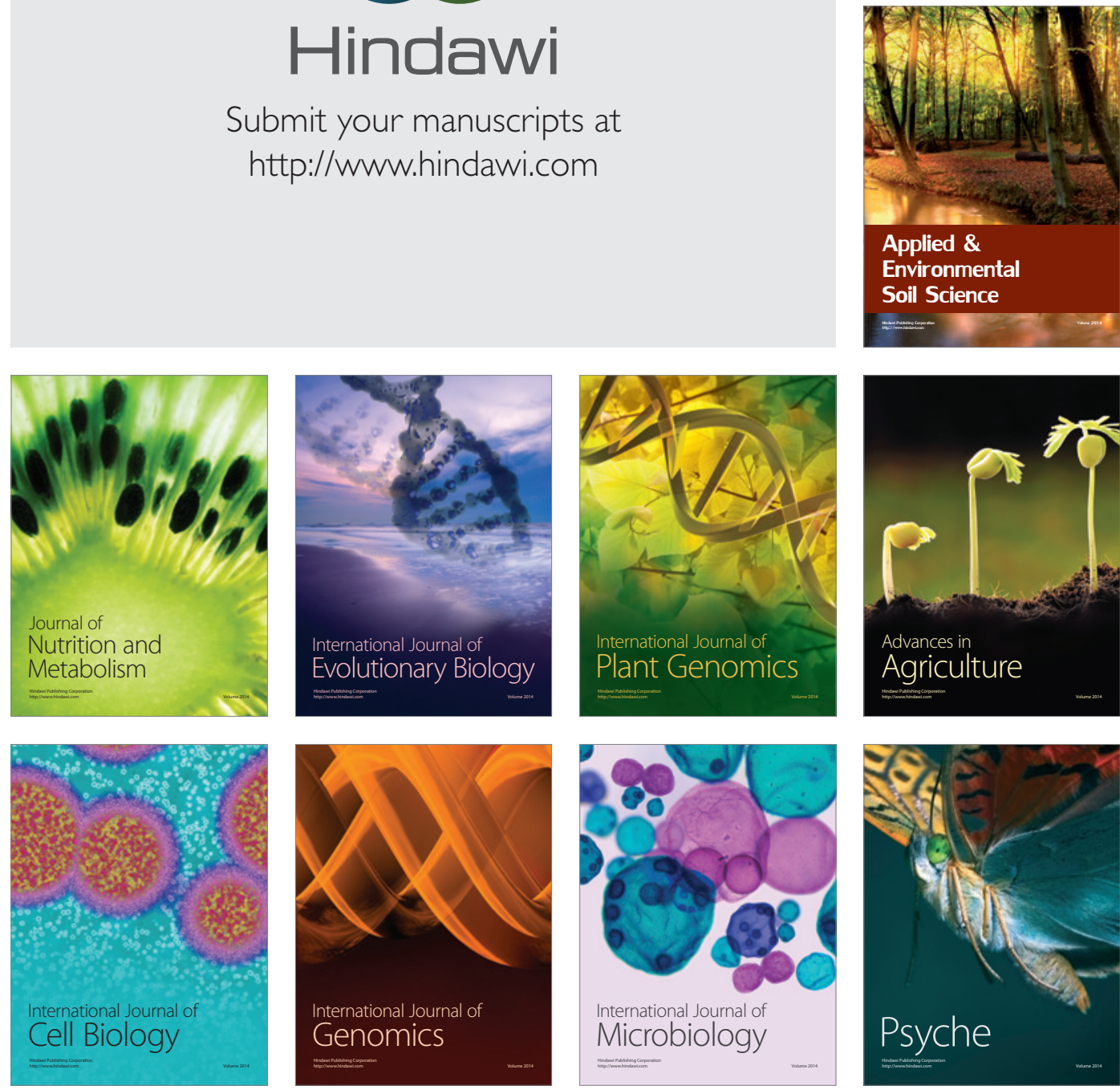
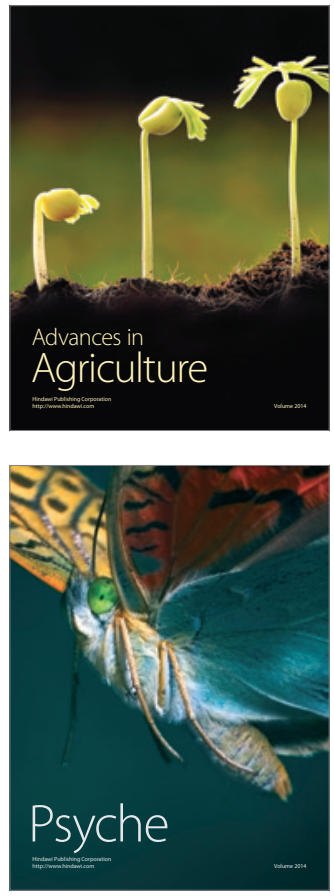